\title{
EGODOCUMENTOS: OS DOCUMENTOS QUE EXPRESSAM A PERSONALIDADE, INTIMIDADE E MOTIVAÇÕES DOS TITULARES DE ARQUIVOS PESSOAIS
}

\author{
AUGUSTO CÉSAR LUIZ BRITTO* \\ ANALAURA CORRADI ${ }^{*}$
}

\begin{abstract}
RESUMO
O presente trabalho constitui-se em uma revisão de literatura do tema "egodocumento", tendo como subsídio a historiografia holandesa que originou e aprofundou o termo e as publicações nacionais recentes na área da comunicação, linguística e historiografia. A pesquisa originouse após a leitura do livro de Camargo e Goulart (2007), que, ao abordarem os Arquivos Pessoais, citam os egodocumentos como aqueles documentos em que a intimidade e motivações dos titulares dos arquivos se fazem presente no processo de narrar a sua vida. A falta de um estudo mais abrangente sobre os "egodocumentos", dentro da perspectiva arquivística, motivou a revisão da literatura principalmente ao que tange a história do termo, os conceitos enunciados e as principais espécies exemplificadas pelos autores que trabalham com o tema. Esse trabalho busca, portanto, contribuir com a literatura arquivística, principalmente para aqueles interessados em Arquivos Pessoais.
\end{abstract}

PALAVRAS-CHAVE: Egodocumento. Arquivo Pessoal. Arquivo Familiar. Autobiografia.

\begin{abstract}
The present work constitutes a review of the literature on the subject "egodocumento", with the support of the Dutch historiography that originated and deepened the term and the recent national publications in the area of communication, linguistics and historiography. The research originated after the reading of Camargo's and Goulart's (2007) book that when approaching the Personal Archives cite the documents as documents where the intimacy and motivations of the file owners are present in the process of narrating their life. The lack of a more comprehensive study of "egodocuments", within the archival perspective, led to the revision of the literature mainly concerning the history of the term, the concepts enunciated and the main species exemplified by the authors who work on the theme. This work seeks,
\end{abstract}

\footnotetext{
* Universidade da Amazônia. Mestre em Comunicação, Linguagens e Cultura.

** Universidade da Amazônia. Doutora em Ciências Agrárias. Professora titular da Universidade da Amazônia.
} 
therefore, to contribute with the archival literature, mainly for those interested in Personal Archives.

KEYWORDS: Egodocument. Personal Archive. Family Archive. Autobiography.

\section{INTRODUÇÃO}

O termo "Egodocumento", na literatura arquivística, é apresentado no livro "Tempo e Circunstância", de 2007, autoria de Ana Camargo e Silvana Goulart, cuja temática principal é em torno dos Arquivos Pessoais. As autoras conceituam "egodocumentos" como aqueles documentos não tradicionais de procedência administrativa, isso é, documentos oriundos do espaço doméstico e que contêm elementos da personalidade do autor.

Esses são documentos que, por sua essência, formam os Arquivos Pessoais e diferenciam-se dos documentos institucionais, cuja natureza objetiva faz com que as características dos autores não fiquem tanto em evidência. O que define se um documento é ou não um egodocumento é se contém a presença materializada do "eu" do autor no texto.

A personalidade, estando intrínseca nos textos dos egodocumentos, proporciona aos leitores e/ou pesquisadores a possibilidade de perceber as relações afetivas, as devoções, os hábitos, intimidade e as preferências do titular do Arquivo Pessoal. Corroborando com essa linha de raciocínio, Amelang (2005), citado por Mostacero (2006, p. 133), defende que os egodocumentos são aquelas fontes que apresentam "um texto, de qualquer forma ou tamanho, em que se esconde ou descobre deliberadamente ou acidentalmente um ego" (tradução nossa) ${ }^{1}$.

No entanto, o foco do argumento de Carmargo e Goulart (2007) é relatar que esse tipo de documentação não recebe o valor devido pelos arquivistas por conterem, em sua estrutura, o que elas denominam de "zona de penumbra", ou seja, a falta de imposições jurídicas e padronização administrativa (facilmente identificáveis pelas regras da diplomática), que são requisitos para tornar os documentos, principalmente os de caráter institucionais, autênticos e com valor probatório.

Diante desse contexto, os egodocumentos apresentam dificuldades aos arquivistas e profissionais que atuam com esse tipo

\footnotetext{
${ }^{1}$ un texto, de cualquier forma o tamaño, em que se esconde o descubre deliberada o acidentalmente une ego (MOSTACERO, 2006, p. 133).
} 
de documentação quanto ao correto tratamento arquivístico, principalmente em relação ao arranjo, à descrição e à difusão.

Sabe-se que a valorização dos Arquivos Pessoais, principal tipo de fundo que abarca egodocumentos, no Brasil, iniciou-se na década de 1970, exigindo que os profissionais responsáveis pela custódia e tratamento deles aprofundassem o debate que cerca a teoria e os conceitos sobre essa categoria de acervo. As contribuições do Centro de Pesquisa e Documentação Histórica CPDOC da Fundação Getúlio Vargas - FGV, Casa de Oswaldo Cruz - COC da Fundação Oswaldo Cruz - FIOCRUZ e o Museu de Astronomia - MAST e do Instituto Fernando Henrique Cardoso IFHC ajudaram a avançar o entendimento sobre Arquivos Pessoais dentro da perspectiva arquivística.

É necessário, também, compreender os assuntos correlatos abarcados pelos Arquivos Pessoais em ciências afins para que o aprofundamento sobre a temática continue. Nesse sentido, 0 presente artigo apresentará uma discussão sobre o termo "egodocumento" anunciado por Camargo e Goulart (2007) em sua origem, ou seja, na historiografia holandesa, elucidando a trajetória do conceito, os principais aspectos teóricos abordados pelos autores que trabalham com o termo "egodocumento" e as características das espécies documentais mais abordadas.

A revisão teórica iniciou-se com os textos dos historiadores holandeses que originaram o termo "egodocumento" e que criaram grupos de estudos como o "Onderzoeksinstituut Egodocument en Geschiedenis"2: Dekker (1995, 2000, 2002a, 2002b e 2007), Amelang (2002), Baggerman (2002, 2007 e 2010), Fulbrook e Rublack (2010), Greyerz (2010) e Grofße (2015).

Em seguida, a revisão teórica direcionou-se a trabalhos científicos que tratavam sobre o assunto. Os artigos encontrados correspondiam à área da comunicação, linguística e historiografia: Sánchez (2005), Mostacero (2006), Lejeune (2008), Magalhães (2010), Aníbal (2011), Vássina (2011), Macedo (2014), Silva, C. (2015), Costa (2016) e Silva, W. (2016), além de Camargo e Goulart (2007), texto anteriormente citado, da área arquivística que deu origem a essa pesquisa.

Uma maior assimilação sobre o que são os "egodocumentos" objetiva ajudar os arquivistas a identificar elementos intrínsecos presentes nos acervos de Arquivos Pessoais, contribuindo para o tratamento arquivístico que possibilite a disponibilização deles para

\footnotetext{
${ }^{2}$ Instituto de Pesquisa Egodocumento e História.
} 
a consulta da comunidade científica. Por conterem as características íntimas e específicas da vida dos titulares dos arquivos pessoais, como as suas correspondências e os diários - egodocumentos por excelência, por exemplo, são esses documentos que se aproximam do caráter autobiográfico. É justamente nesses documentos, de acordo com Camargo (2009), que é possível sentir as diversas motivações dos autores.

\section{A HISTÓRIA DOS EGODOCUMENTOS}

Os textos de caráter autobiográfico, essência dos egodocumentos, tiveram dois momentos significantes quanto ao aparecimento e aumento de suas produções. A "primeira revolução" ocorreu durante o período do Renascimento, no século XVI, quando se fez perceptível um maior volume de textos escritos em primeira pessoa cujo foco era a experiência do autor.

Amelang (2002) argumenta que essa mudança não teve apenas um caráter quantitativo, mas também qualitativo devido às novas expressões que representariam as atitudes do individualismo e da autoconsciência. Porém, o mesmo autor comenta que foi apenas no século XVIII, com os trabalhos de Rosseau e Goethe, que esses textos foram considerados reflexos dos tempos modernos.

Essas fontes documentais, na qual pesa o caráter identitário, era comum estarem preservadas nos denominados "Arquivos Familiares"3. Os nobres eram quem possuíam esses acervos, pois investiam na memória coletiva, segundo sua perspectiva, pelo acúmulo de documentos. No final do século XVIII, Baggerman (2002; 2010) relata que a burguesia, conseguindo cada vez mais destaque na vida social e política, concomitantemente com 0 aumento da individualidade (o privado se distanciando do público), também começou a guardar documentos, formando os seus Arquivos Familiares. A capacidade de escrever por um número maior de pessoas, no século XVIII, fez com que aumentasse ainda mais a produção de egodocumentos (DEKKER, 2007).

A historiografia política tradicional ${ }^{4}$, que primava pelos grandes

\footnotetext{
${ }^{3}$ Arquivo privado de uma família ou de seus membros, relativo às suas atividades públicas e privadas, inclusive à administração de seus bens. Também chamado arquivo familial ou arquivo familiar (DBTA, 2005, p. 29).

${ }^{4}$ Ramo da história que contém como núcleo norteador o "poder". Antigamente essa corrente apresentava a história das grandes personalidades, mas a partir dos anos 1980 a discussão também estuda os micropoderes do cotidiano e não apenas mais o
} 
personagens e seus feitos, confiava nos testemunhos contidos nos egodocumentos. Segundo Dekker (2002a), os historiadores acreditavam que, quanto "mais perto" o sujeito estava do fato histórico, mais verídico era o seu relato e, assim, os egodocumentos assumiam um destaque entre os diferentes tipos de fontes documentais.

Aliás, essa concepção de testemunho ocular como fonte importantíssima para memória origina-se no início da disciplina histórica na Grécia Antiga. Heródoto e Tucídides utilizaram em seus trabalhos as narrativas sobre os eventos sobre os quais escreveram como fonte (AMELANG, 2002).

Porém, no século XIX, período em que a história adquiriu status científico, os egodocumentos não são mais considerados fontes confiáveis para a construção historiográfica. Ranke, de acordo com Dekker (2002a, p. 21), foi um dos primeiros a alertar sobre os perigos desses documentos, nos quais continham elementos literários devido ao subjetivismo e ao caráter ficcional intrínseco a eles. Dekker (2002a, p. 21) relata que os historiadores alemães e ingleses daquela época chamavam a atenção para que "em todos esses textos, a verdade foi citada pelos próprios autores ou por seus editores (tradução nossa)" .

Até as primeiras décadas do século $X X$, os egodocumentos eram considerados, portanto, pelos historiadores tradicionais, econômicos e sociais, como documentos de pouca confiança e utilidade já que sofria influência dos responsáveis pela sua produção.

A segunda revolução autobiográfica procedeu-se no século $\mathrm{XX}$, porém, dessa vez, não somente como mais uma maneira de se escrever, mas também como fonte crível para as pesquisas historiográficas. Interpreta-se a primeira revolução como sendo resultado da história de seu tempo e a segunda revolução como apropriação historiográfica (AMELANG, 2002).

Somente na primeira guerra mundial é que, de fato, ocorreu um "boom" do surgimento de vários tipos de egodocumentos e, consequentemente, a reflexão sobre esse tipo de fonte. A quantidade de textos, das tipologias e qualidade deles, conforme relata Amelang (2002), marcam essa nova revolução. Aparece o debate sobre o caráter de "testemunho" desses documentos que se apresentavam cada vez mais com uma tônica pessoal do que os egodocumentos de épocas anteriores.

poder das elites (BURKE, 1997).

${ }^{5}$ In all these texts the truth had been teisted by the authors themselves or by their editors (Dekker, 2002a, p. 21). 
As guerras, assim como os períodos de crise, impulsionam as pessoas a escreverem sobre si, como relata Dekker (2007), ao comentar o inventário de autobiografias holandesas elaborado por ele e seu grupo de estudo. Outro fator impulsionador destacado pelo autor é em relação à religiosidade, pois essa estimula a introspecção.

A obra "O camponês Polaco na Europa e na América", de autoria de Znaniecki e Thomas (1920), é considerada o primeiro trabalho científico que se subsidiou, sistematicamente, mediante análises de documentos pessoais (MACEDO, 2014).

Os autores tinham como intuito a análise das visões de mundo via narrativas dos polacos que emigraram para os EUA durante a primeira guerra mundial. Devido ao impedimento do contato dos autores com os indivíduos, que eram seu objeto de estudo, optaram por analisar a autobiografia desses sujeitos.

Nos anos 1940, Marc Bloch, historiador alemão, apresentou especial atenção a autobiografias como fonte para a história. O autor foi um dos principais historiadores da época, segundo Amelang (2002), que defenderam a ideia de que esse tipo de documento deveria ser analisado como "testemunho", chegando até mesmo a classificar egodocumento como uma categoria diferente de fonte histórica.

Como testemunho, o autor argumentava que as fontes em si também devem ser investigadas, exigindo, dessa maneira, um papel ativo do historiador. Amelang (2002) comenta que Bloch provocou um rompimento em relação à visão que se tinha na história ao retomar a falsa ideia sobre a verdade automática dos testemunhos oculares. $O$ próprio método histórico de análise precisou de uma revisão.

Destaca-se que a denominação "egodocumento" para textos narrados em primeira pessoa surge com o historiador holandês "Jaques Presser" na década de 1950. Interessado por textos cujo conteúdo tinha teor autobiográfico como as agendas, diários, memórias e cartas pessoais, Presser precisou definir um termo que englobasse as características dessas fontes:

Ele definiu egodocumentos como "aquelas fontes históricas em que o pesquisador se depara com um "eu", ou ocasionalmente um "ele", como o sujeito que escreve e descreve com uma presença contínua no texto" (Dekker, 2002a, p. 14, tradução nossa) ${ }^{6}$

\footnotetext{
${ }^{6} \mathrm{He}$ defined egodocuments as 'those historical sources in wich the researcher is faced with an "l", or occasionally a "he", as the writing and describing subject witch a continuous presence in the text' (Dekker, 2002a, p. 14).
} 
Dekker (2002) pontua a obrigatoriedade da presença da individualidade do autor, característica própria dos textos autobiográficos, como requisito para ser um egodocumento mesmo que a escrita tenha sido realizada na terceira pessoa. Destaca-se, portanto, que o importante é o escritor presente como sujeito e objeto nos conteúdos dessas fontes.

Pouco tempo depois, Presser, como afirmado por Dekker (2002a), redefine o termo egodocumento, de maneira sucinta, relacionando-o com a presença no texto de um "ego" "aqueles documentos em que um ego se revela deliberadamente ou acidentalmente ou se esconde." (DEKKER, 2002a, p. 14, tradução nossa) ${ }^{7}$.

A expressão "egodocumento" foi cunhada por Presser após ele trabalhar com testemunhos de sobreviventes da polícia Nazista de extermínio. Fulbrook e Rublack (2010) relatam que, apesar do amplo interesse de Presser por esse tipo de fonte, ele estava consciente das possíveis lacunas e silêncios que os testemunhos poderiam ter. Mesmo assim, o autor compreendia que as experiências subjetivas contidas nos egodocumentos poderiam, sim, ser trabalhadas desde que de forma apropriada.

O termo "egodocumento" extrapola as fronteiras da Holanda e é aceito em outras escolas historiográficas, como a Alemã e a Britânica, mediante os historiadores Burke, Lindemann, Schulze e Beaurespaire (Dekker, 2002a, p. 13). Apesar da aceitação do termo "egodocumento" e da notoriedade que o mesmo recebeu, a popularidade não foi na mesma intensidade. Nesse mesmo período, as fontes abarcadas pelos egodocumentos se ampliavam devido à percepção da existência de um "ego" em documentos de origem jurídica (GROF $\beta E, 2015$, p. 23).

A história econômica e social ${ }^{8}$ adquiriu mais adeptos naquele momento e começava a predominar na área historiográfica. Essa se caracteriza por ser uma história geral e das coletividades na qual a individualidade típica dos egodocumentos não encontraria espaço nessa maneira de ver e contar história. Além disso, essa história era "rotulada" e "interpretada" como uma "microhistória", "pós-

\footnotetext{
7 those documents in which an ego deliberately or accidenrally discloses or hides itself..." (DEKKER, 2002a, p. 14).

8 Ramo da história que contém como núcleos norteadores a "economia" e a "sociedade". Aplica-se as teorias da Ciência Econômica com os métodos historiográficos sobrepondo-se a história social (BURKE, 1997).

${ }^{9}$ Ramo da história cuja análise se processa mediante uma delimitação intensamente especifica de seu tema (objeto, espaço e tempo). Essa corrente historiográfica
} 
modernismo"10" e "renascimento da narrativa na história" como preconizava a história do século XIX de Ranke (AMELANG, 2002).

Outro enfoque dos historiadores é sobre a forma de tratamento dos egodocumentos como fonte dos estudos históricos. Destacaram-se as formas de interpretações e, até mesmo, enquadramento entre história e literatura e entre documento informativo ou de ficção. Os egodocumentos não seriam textos que proporcionavam os fatos de forma bruta, pois, como qualquer outro tipo de texto, eles precisavam passar por processos de revisão e edição, sendo passíveis de várias interpretações. Mediante essas variáveis, Dekker (2002a) comenta que alguns desses historiadores entendiam os egodocumentos não como uma simples fonte historiográfica, pois eles se aproximariam mais da literatura por ter um suposto lado ficcional no qual a verdade era desvirtuada, conscientemente ou não.

Vássima (2011) e Silva (2015) corroboram com essa questão ao comentar que, ao narrar nossas memórias, "aplicaríamos a nós mesmos conceito de vozes narrativas que constituem as intrigas das epopéias, das tragédias, dos dramas e das novelas". Devido à aproximação com o ficcional, os egodocumentos eram considerados de menor valor (SILVA, 2015).

Os egodocumentos começam a readquirir algum status com o surgimento da "história das idéias"11 e/ou "história das mentalidades". Esses se basearam nos enunciados de Dilthey, no final do século XIX, onde o autor defendia o uso de documentos escritos em primeira pessoa enquanto fonte de pesquisa historiográfica. Segundo Amelang (2002), o uso de autobiografias em relação ao individual e particular para Dilthey era a maneira de combater a noção monolítica e uniforme de vida tanto no passado como no presente. Seu pupilo, Misch, de acordo com Dekker (2002a, p. 22), estudou mais profundamente os documentos autobiográficos, os quais considerava como prática cultural em que o escrevente exibia publicamente a sua identidade. Para esse autor,

privilegia agentes sociais até então considerados como figurantes pela história tradicional (BURKE, 1997).

${ }^{10}$ Momento, pós década de 1970, no qual a historiografia sofre com a ausência de um único paradigma. A história ao invés de ter um único sentido possui na verdade vários, pois os objetos de estudo da pós-modernidade formam a história total (CHARTIER, 1994).

${ }^{11}$ Ramo da história que estuda o sistema de crenças, de valores e de representação de uma coletividade numa época especifica. Analisam-se os modos de pensar, compreensão e os sentidos da coletividade em estudo (CHARTIER, 1994). 
a identidade do eu é flexível, aberta a múltiplas interpretações e historicamente determinada.

Em 1980, retomam-se os estudos sobre esse tipo de documento via narrativa historiográfica dos Annales ${ }^{12}$, desencadeando uma reavaliação dos egodocumentos como fonte para história (Dekker, 2002a). Retornava, em consequência dessa crítica, a narrativa historiográfica.

Greyers (2010) comenta que o impacto que teve a historiografia durante o processo de mudança da "história social"13 em direção à "história cultural" 14 foi tão marcante que a metodologia apropriada até então pelos historiadores foi, quase na íntegra, destruída. $\mathrm{O}$ autor comenta sobre a consciência que se tinha sobre os limites dos egodocumentos enquanto fonte:

Fomos fortes e repetidamente alertados para o fato de que esta fonte material é em grande parte construída, e que, como resultado, oferece pouco acesso direto às preocupações e pensamentos diários, e muito menos às ações do autor sendo estudado (GREYERZ, 2010, p. 275, tradução nossa). ${ }^{15}$

Além disso, tendo como base os estudos dos Foucaultianos e Linguistas, é lembrado que os egodocumentos produzem uma linguagem e terminologia que externalizam, dentro de um formato, o individualismo consciente que, por sua vez, expressa a essência coletiva do social (GREYERZ, 2010, p. 275).

A crítica que se tinha até então da falta de representação dos egodocumentos foi contornada quando essas fontes foram comparadas com outras biografias ou mesmo outro tipo de fonte. Os egodocumentos, para serem confiáveis e representativos, devem ser, na análise, contextualizados:

\footnotetext{
12 Escola historiográfica que propôs uma nova forma de escrever história opondo-se ao simples relato de crônicas de acontecimentos. Iniciam-se assim análises historiográficas que abrangiam a "longa duração do tempo" no qual permitia a maior e melhor compreensão das mentalidades e demais aspectos da sociedade em estudo (BURKE, 1997).

${ }^{13}$ Ramo da história que estuda as classes menos favorecidas, "as grandes massas", na sociedade em oposição à história das elites objeto de estudo da história tradicional (CHARTIER, 1994).

${ }^{14}$ Ramo da história que contém como núcleo norteador a "cultura popular". O objeto de estudo é em torno da representação de determinada cultura de uma sociedade e época delimitada (BURKE, 1997).

${ }^{15}$ We were strongly and repeatedly alerted to the fact that this source material is by and large constructed, and that, as a result, it offers little direct access to the daily concerns and thoughts, lets alone the actions, of the author being studied (GREYERZ, 2010, p. 275).
} 
Egodocumentos não devem ser considerados apenas como uma fonte de onde os fatos podem ser extraídos, mas a função de tais textos dentro de seu contexto social também deve ser levada em conta (DEKKER, 2002a, p. 25). ${ }^{16}$

Historiadores da micro-história, por sua vez, preocupavam-se com a análise do texto individual em si e não com a questão da não representatividade dos egodocumentos. Destacam-se os estudos realizados por esses historiadores em interrogatórios judiciais, que eram considerados como texto que contém aspectos autobiográficos.

Egodocumento, como conceito, foi retomado e consolidado por Rudolf Dekker na década de 1980 (GROFßE, 2015). Dekker, como relata Baggerman (2010) inicia, em 1983, uma inventariação com seu grupo de estudo das autobiografias da Holanda do período de 1600-1914. Posteriormente, grupos de estudos de vários países Europeus seguiram o exemplo de Dekker (GREYES, 2010).

Mostacero (2006) aborda que a atenção em estudar as escritas em primeira pessoa é recente e que, além dos historiadores, também os paleógrafos, arquivistas e linguistas têm interesse em analisar os egodocumentos. A dificuldade de acesso é a barreira que limita maiores estudos, pois, conforme Dekker (2000), grande parte dos egodocumentos ainda continua preservada em Arquivos Familiares ou nas mãos de colecionadores de manuscritos. Nesse sentindo, trabalho que inventarie a existência desse tipo de documento se faz de suma importância.

Amelang (2002, p. 104) relata que, apesar da mudança paradigmática em relação aos egodocumentos, chegando esses, até mesmo, a estarem em posição privilegiada entre as demais fontes documentais, os historiadores e demais pesquisadores que se utilizam desses não apresentaram grandes reflexões teóricas e conceituais sobre:

Obviamente, muita água fluiu sob a ponte, e atualmente a autobiografia ocupa, para melhor ou para pior, uma posição de privilégio dentro da hierarquia das fontes. O atual "triunfo da autobiografia", entretanto, não significa que nós, historiadores, tenhamos uma compreensão muito mais profunda das origens, propósito e funcionamento da escrita em primeira pessoa.

\footnotetext{
${ }^{16}$ Egodocuments should not only be regarded as a source from wich facts can be extracted, but the function of such texts within their social context should also be taken into account (DEKKER, 2002a, p. 25).
} 
Ironicamente, a segunda revolução autobiográfica foi acompanhada por pouca reflexão sistemática por historiadores e outros estudiosos sobre o potencial e as limitações inerentes ao uso de textos autobiográficos como fontes (AMELANG, 2002, p. 104, tradução nossa $)^{17}$.

Exemplificado o uso dos egodocumentos, há a cidade italiana de "Pieve Santo Stefano", que, de acordo com Macedo (2014), tornou-se a "Cidade do Diário". A cidade ficou conhecida como a capital da memória privada, após a fundação por Saveio Tutino de um "Centro de Acolhimento" de escritos biográficos e diários onde diferentes pessoas vão e depositam seus textos. O incentivo para essa criação surge da necessidade da localidade em "ter" uma memória coletiva após ter sido destruída por minas alemãs na Segunda Guerra Mundial.

\section{CONCEITO, CARACTERÍSTICAS E ESPÉCIES DE EGODOCUMENTOS}

A definição do que são os egodocumentos é melhor compreendida com os conceitos elaborados pelos autores que trabalham com esse termo. O primeiro a apresentar "egodocumento" em seus textos como um tipo diferenciado de documentos, como citado anteriormente, foi o historiador holandês Jacob Presser em 1958 (MOSTACERO, 2006; SILVA, 2015).

A vida pessoal de Presser direcionou-o a investigar sobre o potencial dessas fontes. Greyerz (2010) relata que Presser, durante a segunda guerra mundial, precisou se esconder da polícia alemã por ser judeu, porém não conseguiu evitar que sua esposa fosse deportada. Em 1950, já posteriormente à guerra, foi designado a escrever sobre a história dos judeus holandeses durante a ocupação alemã pelo Instituto Estatal Holandês para Documentação de Guerra (Greyerz, 2010, p. 278, tradução nossa). ${ }^{18}$ Ele teve acesso a

\footnotetext{
17 Obviously, much water has flowed under the bridge, ad nowadays autobiography occupies, for better or worse, a position of privilegie within the hierarchy of sources. The presente-day "triumph of autobiography", however, does not mean that we historians have a much deeper understanding of the origins, purpose, and workings of first-person writing. Ironically, the second autobiographical revolution has been accompanied by little systematic reflection by historians and other scholars of the potential of, and limitations inherent to, the use of autobiographical texts as sources (AMELANG, 2002, p. 104).

${ }_{18}$ Founded Netherlands State Institute for War Documentation (GREYERZ, 2010, p. 278).
} 
documentos de vítimas e perpetradores do holocausto nos quais dedicou atenção a ambos, resultando dessa pesquisa duas publicações.

O que diferencia egodocumentos dos demais documentos é justamente a questão da personalidade do autor se fazendo presente no texto. Presser, quando fala de sentimento, coloca-o de maneira universal, pois, nesse rol, podem aparecer os mais diversos nos egodocumentos: felicidade, orgulho, decepção, frustação, modéstia, entre outros. Aníbal (2011) comenta que esses sentimentos tornam a escrita mais retrospectiva e reflexiva. Seja qual for o tipo de egodocumento, os textos neles presentes contêm marcas dos indivíduos representadas pelas falas de si, os sentimentos ou a visão do mundo sobre um fato e/ou da sociedade onde estes estão inseridos. A diferença de um texto para o outro é decorrente das variáveis de quem é o autor que escreve e se apresenta: idade, gênero, classe social, nível de letramento, profissão e outros (GROFßE, 2015).

É o ego em forma de intenções biográficas do autor que se expõe em condição de documento. Dentro dessa perspectiva, Grofße (2015) aborda que o escritor estará sempre presente no texto como sujeito mediante o "eu". São justamente as ações e sentimentos relatados desse "eu" que abrem margem ampla de interpretações sobre a personalidade de quem escreve e descreve suas ações como relatado por Baggerman (2010).

Schulze, em seus estudos, aprofunda o conceito sobre egodocumentos. Os textos autobiográficos, para o autor, fazem uma referência à imagem que os próprios autores fazem de si mesmos (MOSTACERO, 2006). Também é Schulze que dilata o leque de fontes consideradas como egodocumentos ao abordar sobre documentos nos quais não era a intenção falar sobre o "eu", porém esse "eu" se faz de alguma maneira presente como no caso de documentos judiciais e administrativos.

Ao perceber que documentos institucionais também poderiam ter elementos perceptíveis do "eu", consequentemente, abria-se uma variável significativa para qualquer tipo de documento ser passível de ser egodocumento (SILVA, 2016). O que importava para Schulze eram as "marcas presentes no texto do eu" no qual se denomina de "egopercepção". Grofße (2015) explica a "ego-percepção" como a perspectiva individual e subjetiva do autor que se faz presente nos documentos mesmo que de maneira inconsciente.

Um exemplo de documento administrativo que contém elementos pessoais que os caracterizam como egodocumentos são 
os memoriais acadêmicos trabalhado por Silva (2016). O autor comenta que esses documentos incorporam uma dimensão subjetiva na narrativa a qual o sujeito tem maior foco mesmo dentro de uma linguagem burocrática, formal, cientificamente ponderada e tecnicamente equilibrada, que é exigida pelos memorais acadêmicos.

Essa reflexão contradiz a afirmação de Macedo (2014, p. 44), quando a autora afirma que os egodocumentos são "produzidos, duma maneira geral, internamente, isto é, fora do quadro institucional ou oficial e que testemunham a posição de alguém sobre si mesmo, sobre os seus, a sua comunidade". Ela desconsidera, quase que por completo, os documentos administrativos e judiciais. Interessante é a forma de transmissão dos egodocumentos, na qual a autora elenca em sequência: de pais para filhos, profundezas de um armário ou reaproveitamento do livro como caderno de despesas e receitas. Mais uma vez, os documentos institucionais são impossibilitados de serem considerados como egodocumentos pela autora.

De qualquer forma, é perceptível que a proveniência e a constituição de fundo poderão variar. Os Arquivos Pessoais serão os principais tipos de fundos que conterão egodocumentos em seus conjuntos documentais, porém fundos institucionais também são passíveis de receber esse tipo de fonte. Consequentemente, a proveniência que mais produz egodocumentos são os titulares de acervo pessoais, porém arquivos institucionais em menor escala são capazes de gerá-los.

Egodocumentos em essência, se comparados com documentos institucionais ou textos filosóficos e literários, são aqueles que apresentam maior grau de subjetividade. Mostacero (2006) comenta sobre a existência de uma "hibridação dentro de um continuum", ou seja, que os diversos textos, independente de sua natureza, pública ou privada, apresentam traços pessoais dos autores. Ele exemplifica com um livro acadêmico do sociólogo e linguista francês Roland Barthes, demonstra que esse está mais próximo dos egodocumentos do que do rigor científico. Esse exemplo está de acordo com a arguição de Dekker (1995) sobre a possibilidade de alguns tipos de egodocumentos conterem o público e o privado entrelaçados. Nessa mesma perspectiva, Mostacero (2006) argumenta:

Mas se é isso que ocorre no ambiente acadêmico, que nada mais é do que um setor público teríamos que ver como eles aparecem na esfera pessoal e privada. A norma também aceita textos expressivos, 
metafóricos e até subjetivos para certos textos literários e de ensaio, como monografias, mas os parâmetros de objetividade/subjetividade não são regularmente distribuídos e são adequados para distinguir textos das esferas pública e privada (Mostacero, 2006, p. 132, tradução nossa) $)^{19}$.

Escritas autobiográficas foram, por muito tempo, consideradas "o espelho da alma" por representar a real face de quem escreve e não sofreria interferências externas. Essa ideia, que elevava o status desse tipo de fonte, tinha como modelo a obra "Jean-Jacques Rousseau's Confessions" e, posteriormente, a "Confessions of Augustine", de Rosseau e Saint Augustine respectivamente, pois se acreditava que qualidades como sinceridade, autenticidade, introspecção, apresentadas nesses livros, estariam presentes nos documentos em sua forma plena (BAGGERMAN, 2002; 2010).

Acontece que cada egodocumento é produto de seu tempo, ou seja, interage com a sociedade e seus valores em diferentes épocas. Valores que se acreditavam necessários em certa época podem variar através do tempo. Decorrente disso, Magalhães (2010) aponta que esse tipo de fonte dá sentido a uma "ego-escrita" noticiosa, afetiva, familiar e pessoal. Existe, assim, uma troca entre o mundo exterior e o privado do autor que toma forma nessas fontes e, por isso, as qualidades que eram citadas inicialmente como características essenciais dos egodocumentos nem sempre estarão presentes:

Estes registros contêm e representam uma mesologia, essa zona
cartográfica e cognitiva onde a exterioridade se cruza e alimenta um
interior informado, sentimental, angustiado e inquieto, mas também
onde o público se torna notícia e ganha significado, através da
realização do privado (MAGALHÃES, 2010, p. 3).

Estudos oriundos da psicologia, tendo como base Freud, e da literatura corroboram com esse pensamento ao mostrar que essas escritas são influenciadas por convenções sociais e literárias (externo). Essas fontes apresentam variáveis em suas problemáticas que a distanciam de ser um simples retrato da

\footnotetext{
19 Pero si esto es lo que ocorre en el ambiente académico, que no es más que un sector público, habría que ver como se presentan en el ámbito personal y privado. La norma, igualmente, acepta uma escritura expressiva, metafórica y hasta subjectiva, para ciertos textos literários y ensayísticos, como la monografia, , pero los parâmetros de objetividade/subjetividade no están regularmente distribuídos i son adecuados para distinguir textos del ámbito público y privado (Mostacero, 2006, p. 132).
} 
personalidade daquele que escreve. Fulbrook e Rublack (2010) apontam a existência de um fascinante e sofisticado debate sobre "individualidade" e "personalidade" na historiografia alemã, que surgiu após aprofundamento do uso de egodocumentos. Baggerman (2002) argumenta que, mesmo um século depois do aparecimento da obra de Rousseau's e dos posteriores estudos autobiográficos, ainda se acredita que essas fontes são as mais fidedignas em conteúdo pessoal em detrimento das demais.

Um exemplo são os jornais holandeses de viagem trabalhados por Dekker (1995), o autor conclui que essas escritas autobiográficas eram produzidas para contar os feitos dos autores aos outros. Os egodocumentos em questão contêm o "eu" característico dessas fontes presentes, por terem como fator externo determinante um destinatário que não a si próprio, diferente, caso fosse um diário convencional, ruídos na representação da personalidade provavelmente aparecerão. A imagem que se deseja passar ao outro é mais importante do que as características reais da personalidade e até mesmo os diários podem ser escritos para outros, como Baggerman (2002) exemplifica ao citar um caso de um pai que escreve seu diário para seu filho ler no futuro.

O próprio Presser, desde que alcunhou o termo egodocumento, sabia que esse, como categoria de fonte, tinha problemáticas implícitas que deveriam ser consideradas ao serem estudadas. Ele lembra que as memórias escritas ou orais são contadas de acordo com as conveniências daqueles que as relatam e, assim, eles podem mudar, conscientemente ou inconscientemente, as narrativas. Para a pesquisa ser completa e mais aprofundada para Presser, os egodocumentos deveriam ser cruzados com outros tipos de fontes correlatas (GREYERZ, 2010).

Na mesma linha de interpretação, Schulze argumenta sobre a impossibilidade de encontrar a totalidade de um "ego" em um único documento (GREYERZ, 2010). Dependendo do que o autor quis transmitir em suas linhas, apenas alguns aspectos do eu estarão latentes e eles ainda podem ser frutos de uma intencionalidade.

Fulbrook e Rublack (2010) também questionam se os egodocumentos podem permitir-nos acessar a personalidade do escrevente. Os autores admitem que o entendimento de experiências pessoais são possibilitadas com as leituras dessas fontes, porém é necessário procurar compreender sobre como se encontrava a individualidade e a personalidade do sujeito, se em fase de mudanças ou coesa, que se deseja estudar no momento em que este escreveu sobre si mesmo.

Quanto mais antigo o documento é, maior a dificuldade de se 
encontrar um ego como relatado por Freud. Greyerz (2010) comenta que os documentos do século $X X$, os quais podemos facilmente contextualizar o seu conteúdo, são aqueles de maior possibilidade de acesso à personalidade bruta dos autores.

Além da dificuldade de contextualizar documentos mais antigos por parte dos estudiosos, é necessário ter em mente que os autores de egodocumentos relatam alguns aspectos de sua vida privada mediante uma perspectiva que deseja que fique perpetuada, ou seja, é a reprodução interpretada da sua realidade social exprimidas por palavras escritas como argumentado por Macedo (2014). Por esse motivo, Greyerz (2010) prefere chamar esses documentos de "Narrativas do eu" ou "Narrativas Pessoais". Essas narrativas em sua construção sofrem influências: social, linguística, cultural e material e, por isso, o mesmo autor conclui que os egodocumentos falam mais sobre os grupos os quais o autor integra do que sobre a sua individualidade.

As individualidades e personalidades relacionam-se a um gênero e veículo de expressão de sua mensagem, as quais podem variar com o passar do tempo. Porém, provavelmente nenhum gênero e veículo de expressão conseguirão transmitir além de vislumbres do verdadeiro eu do autor ou parcela daquilo que deseja perpetuar sobre si:

Os documentos do ego podem (parecer) vislumbres íntimos de uma pessoa, ou pelo menos permitir que nos engajemos de alguma forma (reconhecidamente apenas unidirecional) na comunicação intersubjetiva com um indivíduo histórico, fornecendo insights sobre a natureza da experiência subjetiva em modo de histórias concentradas, por exemplo, altos índices políticos ou econômicos ou mudanças não estruturais. Dar voz a certos indivíduos do passado pode até constituir uma grande medida do motivo de escrita do historiador (FULBROCK e RUBLACK, 2010, p. 265, tradução nossa $)^{20}$.

Ou seja, aproximamo-nos mais das razões que levam alguém a escrever sobre si dentro do contexto daquele momento do que

\footnotetext{
${ }^{20}$ Ego-documents may (appear to) convery intimate glimpses of a person, or at least allow us to engage in some form (admittedly only one-way) inter-subjective communication with a historical individual, providing insights into the nature of subjective experience in the way that histories focusing on, for example, high politics or economic índices or structural changes do not. Giving voice to certain individuals from the past may even constitute a large measure of the historian's motive for writing (FULBROCK; RUBLACK, 2010, p. 265)
} 
acerca da real individualidade. Perguntas como "quem escreveu esses documentos?", "qual a razão de escrevê-los?", "como eles foram escritos?" e "quem eram os destinatários dessas escritas?", de acordo com Dekker (1995), são primordiais para a compreensão de tudo que cercou os egodocumentos a serem analisados e repercutiu neles. A autonomia reflexiva dos autores, portanto, é limitada, pois, conforme Aníbal (2011), ela "está constrangida pelos enquadramentos estruturais em que estes se situam e que lhes permitem aceder, ou não, aos recursos disponíveis", isto é, o contexto em que as reflexões individuais se moldam delimita as condutas dos autores. Nesse sentido, podemos estudar os egodocumentos em três perspectivas diferentes de acordo com Grofße (2015): individual, social e transcultural.

Importante destacar a presença de marcos da vida pessoal do autor que são refletidas nos egodocumentos. No decorrer dos anos, os indivíduos são obrigados, em certas circunstâncias, a ter que realizar decisões que afetarão o resto de suas vidas e de quem os acompanha. Aníbal (2011) denomina esses períodos como "bifurcações", pois são momentos de rupturas e/ou crise que potencializam o indivíduo a aprendizagens e reflexões. O mesmo autor cita Bessin; Bidart; Grossetti (2009) para elencar as três características fundamentais de uma bifurcação: "i) O caráter súbito; ii) a reconfiguração do espaço de possibilidades; iii) a distinção nítida entre um "antes" e um "depois"'.

As bifurcações são de suma importância para o estudo de uma biografia, pois apresentam vários elementos que refletem os determinismos sociais, culturais, pessoais, físicos e familiares dos indivíduos. Aníbal (2011) ainda comenta que as bifurcações podem ser ativas, resultadas de escolhas deliberadas, ou passivas, fruto das circunstâncias. Deve-se buscar compreender as interações das causas estruturais e individuais para maior compreensão, dentro das possibilidades, do indivíduo a ser estudado.

Baggerman (2010), ao pesquisar autobiografias holandesas do século XIX, aponta algumas das motivações dos autores de egodocumentos. Em sua análise, é interessante a questão das "revisões" realizadas pelos autores das suas autobiografias, anos mais tarde, tendo algumas como produto versões censuradas das mesmas chegando até mesmo, em certos casos, a destruição dos originais. Dependendo da maneira que o indivíduo altera a sua identidade e relacionamentos no mundo, ele recompõe e reenquadra suas escritas de maneira que atenda a essas mudanças. $O$ ato de moldar a identidade em um determinado 
momento relaciona-se muito com o período individual em que o sujeito está vivendo.

Fulbrook e Rublack (2010) comentam que as pessoas se reconhecem de acordo com uma variedade de grupos e normas (família, amigos, idade, corpo, identidade sexual, habilidades, etnia, religião e status) e, decorrente dessas variáveis, eles são mais propensos a conviver com pessoas específicas. Os autores abordam que a subjetividade emerge da conexão estabelecida pelo indivíduo em relação aos demais, associações essas que as pessoas respondem quem são para a coletividade.

O discurso sobre a sua personalidade é moldado pelas normas que regem essas relações. Porém, tanto o reconhecimento sobre si mesmo como os relacionamentos pessoais estão sujeitos à mudança, portanto, devemos esperar que, como relatam Fulbrock e Rublack (2010), as personalidades sejam inconsistentes ao invés de permanecerem constantemente fixas e claras. Os autores concluem que, nesse sentido, os escreventes de egodocumentos criaram e recriaram a sua personalidade em resposta a diferentes grupos, ambientes, gêneros e épocas e, por isso, suas biografias geram tanto encanto.

O caso de autores nazistas é comentado por Fulbrook e Rublack (2010), que, em tempos mais recentes, negaram o apoio ao regime ditatorial em seus discursos, contrastando o que é apresentado em seus egodocumentos daquele período. A variação do tempo, local, propósito e convenções sociais fazem com que indivíduos mudem espontaneamente ou não suas perspectivas, identidades e discursos.

Os autores comentam, ainda, que as diferentes personalidades de uma mesma pessoa, no decorrer do tempo, são como "camadas arqueológicas de significado que não dependem apenas do curso que uma vida particular tomou" (FULBROOK e RUBLACK, 2010, tradução nossa) ${ }^{21}$ e, assim, os resíduos de versões anteriores da individualidade poderão ser discernidos. A própria interpretação de um acontecimento pela mesma pessoa pode variar em momentos distintos como relata Dekker (2002a).

Entre outras motivações para se escrever egodocumentos encontradas por Baggerman (2010) e Silva (2015), em seus estudos, podemos elencar o "controle dos pais", "escrita para gerações futuras", "relatar histórias pessoais e costumes",

\footnotetext{
21 "archaeological layers of meaning, which depend not purely on the actual course a particular life has taken" (FULBROOK; RUBLACK, 2010).
} 
"sentimento de nostalgia ou tristeza", "reflexão sobre a personalidade antiga e atual", "fixar o passado", "necessidade de arquivar a própria vida", "testemunhar", "de se inventar e reinventar", "tomar distância em relação a si próprio". É a necessidade humana de deixar vestígios de sua existência.

Ainda em relação à motivação dos autores em escrever os seus egodocumentos, Aníbal (2011) classifica em três os tipos de egodocumentos:

- Relatos biográficos que resultam da escrita voluntária dos indivíduos sobre a sua própria vida: aqueles egodocumentos escritos espontaneamente e que apenas no futuro é que se tornam objeto de pesquisa. Apresenta a necessidade do autor de refletir sobre momentos passados, acompanhar uma ação momentânea que não se encerrou e atribui sentido para momentos da vida ou mesmo preparar ações futuras. A função dessas escritas para o autor pode ser de apaziguamento, elucidação e/ou reconstrução de si mesmo.

- Relatos biográficos escritos pelo próprio a pedido de investigadores: egodocumentos que fornecem elementos para uma pesquisa mediante um objetivo preciso e um interlocutor.

- Relatos biográficos escritos pelo próprio a pedido de outros interlocutores, em atividades formativas ou de reconhecimento de competências: egodocumentos que respondem a uma solicitação formal para atingir um objetivo instrumental sem a necessidade de reflexão individual. Como exemplo, pode-se citar a "memória descritiva" solicitada em alguns concursos para universidade ou os Portfólios reflexivos de aprendizagem para ascensão na carreira.

Nem todos os documentos escritos ou guardados por alguém são considerados por Aníbal (2011) como egodocumentos. "Escritas do cotidiano" seriam aqueles documentos resultantes da "escrita vulgar", por exemplo, uma lista de mercados, recados, anotações, entre outros. Esses não contêm o caráter autobiográfico, mas são reveladores de uma época. São registros que apresentam elementos contextuais em que o autor viveu em um período e apresentam dados que explicam a sociedade na qual o mesmo se insere.

Os egodocumentos sofrem influência das "tradições discursivas". Grofße (2015) explica que uma língua histórica apresenta convenções de discursos de forma ritualizada, ou seja, o 
modo de escrever e dispor as informações que se deseja repassar recebe um protótipo e são repetidas no decorrer do tempo. O autor classifica em três os níveis de complexidade das tradições discursivas: fórmula simples (exemplifica com os beijinhos no final de e-mails atualmente), gênero textual (carta, por exemplo) ou por um universo discursivo (religioso, literário, entre outros).

No que tange às tradições, são repassadas para novos escreventes pertencentes a uma coletividade. Elas são transmitidas no âmbito escolar, institucional e familiar, além de normas específicas que as regem. Essas tradições influenciam consideravelmente a maneira de se escrever um egodocumento. Necessário, portanto, conhecer os hábitos textuais de cada grupo a ser estudado na época em que existiram.

A forma como se estrutura um egodocumento contribui para a identificação de elementos sobre quem os escrevem. Rutten e Wall, citados por Grofße (2015), relatam que as fórmulas constitutivas de elaboração textual, estudadas por eles, distinguem-se em "Text-type formulae" (saudação inicial e final) e "Text-structural formulae (transição entre dois fragmentos).

Nas "Text-type formulae" são enquadradas as fórmulas de tratamento de um documento e foram mais utilizadas por escritores inexperientes, tendo em vista a redução do esforço redacional que esses proporcionam (GROF $\beta E$, 2015). Porém, são para as "fórmulas intersubjetivas" que os autores chamam a atenção, pois são nelas que encontraremos o nível de aprofundamento do contato social que o escrevente tinha com o destinatário. Como exemplo de "fórmulas intersubjetivas", Grofße (2015) cita as perguntas sobre a saúde e cumprimentos especiais que o autor faz a quem se direciona via documentos.

A existência de uma estrutura identificável em egodocumentos, mesmo que mínimas, relativiza o que Camargo e Goulart (2007) argumentam sobre a falta da existência de imposições jurídicas nesse tipo de documento.

As estruturas básicas dos documentos, na perspectiva da diplomática (protocolo inicial, texto e escatocolo), são fáceis de reconhecer nos documentos administrativos. No caso dos egodocumentos, a disposição informacional de fato não segue à risca uma normativa, porém, inconscientemente, os autores são influenciados pela cultura redacional de sua época e lugar como nos casos dos "formulaes" abordados no texto de Grofße (2015). O Texttype formulae, em sua definição, aproxima-se dos elementos diplomáticos "invocação, titulação, direção e saudação", que constituem 
o protocolo inicial e os elementos "subscrição, datação e precação" do escatocolo, porém redigidos de forma mais espontânea de acordo com a personalidade do escrevente. O Text-structural formulae, na mesma linha de raciocínio, constitui o "texto" nos parâmetros da diplomática. Lembrando que as estruturas diplomáticas, de acordo com Bellotto (2008), evidenciam as coordenadas e as variantes que identificam a tipologia e ajudam na compreensão textual.

Dessa maneira, o "Text-type formulae" e o "Text-structural formulae" dos egodocumentos exercem a mesma função das divisões estruturais consagradas pela diplomática, apesar de não ser obrigada a sua presença no texto. Ambas ajudam na identificação de elementos que contribuem com a contextualização e identificação do documento e de seu conteúdo, facilitando, assim, os usuários em suas pesquisas realizadas.

Devemos considerar que o leitor ou o pesquisador também é agente ativo da construção de memórias pessoais e pode interferir na representação delas. Os egodocumentos, como os demais tipos de textos e fontes, não contêm, em seu público, consumidores passivos facilmente manipulados pela lógica apresentada nas escritas. Baggerman (2007, p. 146) lembra os dizeres de Certeau quando este explica que os leitores são "produtores silenciosos" devido as suas expectativas e carga cultural que induzem significados aos textos aos quais tem acesso.

Logo, os egodocumentos não apenas podem não apresentar o verdadeiro ego, personalidade e individualidade do autor devido a sua intencionalidade, como também o leitor faz inferências àquilo que está escrito, ocasionando, consequentemente, mais de uma interpretação sequencial.

Os autores que trabalham com egodocumentos relacionam como documentos típicos desses várias espécies: cartas, diários pessoais (íntimo, de viagem - viajantes, diplomático, militares ou médico), crônicas (livro) de família, autobiografia, biografia, anais, poemas, almanaques, ensaios, efemérides, monografia, memória, memorial acadêmico, entrevista, testemunho, crônicas, caderno de notas (notas soltas), livros de razão, além dos documentos administrativos e/ou judiciais com informações pessoais, pedaços de papéis e folhas soltas e, atualmente, redes sociais, blogs e sites (AMELANG, 2002. BAGGERMAN, 2007. DEKKER, 2000. GREYERZ, 2010. GROFßE, 2015. MACEDO, 2014. MOSTACERO, 2006. SÁNCHEZ, 2005. SILVA, 2015. SILVA, 2016.).

Tais documentos encontram-se, em quase sua totalidade, nos Arquivos Pessoais juntos aos documentos produtos das atividades 
do titular (COSTA; AMARAL; 2016). Devemos lembrar que um documento, para ser egodocumento, deve apresentar as características pessoais do autor em seu texto e não apenas por ser de uma espécie documental específica.

Em relação à variedade de espécies documentais a serem analisadas, Amelang (2002) e Dekker (2000) citam o perigo sobre as especificidades lexicais e imprecisas das formas de escrita que variam de um para o outro. A análise documental deve atender a essa gama de particularidades para que nem sempre o pesquisador está preparado.

Dekker (2000) conseguiu perceber, em seu estudo, por exemplo, que o gênero textual dos egodocumentos holandeses entre o século XVI e XIX não eram bem definidos e esses eram escritos de várias formas apesar de seguirem algumas regras básicas de apresentação. Os textos eram escritos tanto em primeira quanto em terceira pessoa, tinham várias finalidade (ascensão social, memória viva, correspondência com suas esposas, entre outros). Porém, Amelang (2002) in Greyerz (2010) ressalta que as vantagens são maiores, apesar da não uniformidade do gênero textual, já que o pesquisador poderá analisar um rol de textos mais numeroso que subsidiará e fundamentará sua pesquisa dando maior qualidade a ela.

Especificamente algumas dessas espécies documentais são mais trabalhadas pelos autores. A autobiografia é uma delas. O termo autobiografia é para Dekker (2000) um neologismo do século XIX, apesar de ter iniciado a prática nos séculos anteriores. Lejeune (2008) relata que esses são textos por meio dos quais uma pessoa realiza uma retrospectiva de sua própria existência com ênfase em sua vida individual e em sua personalidade. Silva (2016) comenta que, contemporaneamente, as autobiografias carregam em si dimensões identitárias, públicas, explícitas, instantâneas, personalistas que apresentam o privado, o íntimo e o confessional. Por sua vez, Magalhães (2010) relata que a autobiografia é utilizada pelos autores como apoio às suas memórias e às suas emoções, tendo público-alvo eles próprios e/ou os outros. Porém, essas características são alterdirigida em sua orientação com a finalidade de justificar discursos legitimadores:

Trata-se de uma exposição negociada de identidades individuais e coletivas nas quais o autor, o narrador e o protagonista são a mesma pessoa que se destacam os diversos vínculos propostos em relação aos receptores/leitores, de tal forma a consolidar uma complexa relação entre o eu, o outro e o nós (Silva, 2016, p. 46). 
(Parei)Ao citar Alberti (2005), Silva (2016, p. 46) distingue as autobiografias a outros egodocumentos dos arquivos. Os primeiros seriam "relatos da ação" em forma de memória enquanto os arquivos seriam apenas "resíduos da ação", ou seja, aquilo que ficou como evidência de algo que aconteceu. Porém, o autor comenta que as autobiografias devido a sua intencionalidade também se caracterizam como resíduos de ação.

As cartas são definidas por Grofße (2015) como correspondência ordinária e biográfica que um sujeito escrevente redige para comunicar com os seus familiares ou amigos. Nessas cartas fala-se de algo concreto, das pessoas e/ou de si mesmo. $\mathrm{O}$ autor lembra ainda que nas cartas existem sempre um familiar, uma família ou uma instituição responsável por selecionar, por diversos critérios (temático, estilístico ou emocional), esses documentos cujo objetivo final é perpetuação dos mesmos.

Quanto à análise documental Grofße (2015) comenta que as cartas enquanto egodocumentos devem ser encarados como híbridos e não como homogêneos, pois essas possuem marcas de oralidade e de estruturas próprias de escrita nas quais são produtos da "imediatez" que elas exigem. Paradoxalmente, as cartas possuem estruturas similares entre elas devido à finalidade comunicativa que elas apresentam e que são percebidas principalmente nas introduções e conclusões de seus textos. Isso demonstra, segundo Grofße (2015), que as cartas são uma prática de treinamento sociocultural.

Os diários contêm, por sua vez, predominantemente, a tônica memorialística e são considerados, como Magalhães (2010) argumenta, o principal documento para a "ego-história".

O diário são documentos produtos de um processo de "individualização, de afirmação de uma identidade, de um lugar social, a afirmação de uma individualidade autônoma e soberana" (MACEDO, 2014) que surgiu no século XVI decorrente do Estado moderno que estava se afirmando. O diário funcionava também como auto-exame permanente da individualidade. Dekker (2002a) relata que no século XVIII tem se notícias das primeiras crianças que eram aconselhadas pelos seus pais a escreverem sobre si. Porém, no século XIX foi que os diários se tornaram populares, principalmente após a publicação póstuma do diário da russa Marie Bashkirtseff que começou a escrever quando tinha 15 anos.

Esse foi o período considerado como o da "idade de ouro" deste tipo de texto (MACEDO, 2014) e foi o lar o território ideal para a sua produção, pois era o espaço onde o indivíduo se permitia ser 
si mesmo sem interferências externas. O diário era produto da necessidade humana de situar sua vida dentro de um contexto histórico. Ter um diário nesse período tornou-se "moda" principalmente na burguesia. Para as mulheres, ter um diário era uma maneira de se tornar autônoma, mesmo que um por um instante, registrando reivindicações dentro de um contexto social desfavorável (MACEDO, 2014).

Dekker (2002a) argumenta que durante a segunda guerra mundial proliferou-se a quantidade de diários devido à necessidade de deixar registrada a marca pessoal dos autores num período onde a própria existência pessoal estava sempre ameaçada.

O valor que um diário representava direcionava alguns familiares, em determinados casos, a dar continuidade a eles (esposas, filhos ou biógrafos contratados pelos pais). Baggerman (2010) comenta sobre diários e agendas de viajantes do século 19 que abarcam informações factuais escritos por outros que são complementos às escritas dos autores que deram origem aos mesmos.

Os autores em si dos diários, mesmo que tenham consciência do valor desses documentos, em sua maioria atuavam sem se preocupar com o leitor. Dekker (2000) em seus estudos lembra que a maioria dos diários foram mantidos para o uso do autor sem considerar que um dia esses poderiam ter usuário. Não é de se estranhar a presença de anotações breves e incompletas que dificultam a interpretação, pois para o autor esses bastavam como referência memorialística para si.

Importante ressaltar que um diário pessoal não contém, como nas palavras de Aníbal (2011), nenhuma exigência com a verdade sobre si ou sobre o mundo. Nesse sentido, um pesquisador deve compreender o contexto em que esse diário foi escrito considerando os aspectos estruturais, culturais e conjunturais. Aníbal (2011) lembra ainda que uma história escrita não é necessariamente igual à história vivida, pois a escrita é resultado da interpretação daquilo que o autor relata.

Os blogs nasceram como diário virtual no final da década de 1990 e se consolidaram como ferramenta híbrida (misto de diários e fatos jornalísticos) cuja atualização se processava de forma rápida (SILVA, 2015).

Esses são produtos da revolução proporcionada pelas Tecnologias da Informação iniciada na metade do século XX. Mudanças que não se limitam a tecnologia, mas também na forma como se lê e escreve. Silva (2015) explica que devido à hiperconectividade e o espaço virtual então disponível gerou 
implicações nas "subjetividades, nas relações estabelecidas entre os sujeitos e as temporalidades, os sentidos do passado e de experiência e expectativas de futuro".

Os blogs e as redes sociais, como egodocumentos modernos, invertem a lógica dos diários e das agendas de antigamente que necessitavam de uma distância espacial e temporal em relação aos destinatários ou futuros leitores. Agora, a leitura é instantânea, para a visualização imediata do leitor, ou seja, ao invés da discrição que pautava os diários tradicionais, agora o objetivo é a visibilidade do privado (MACEDO, 2014).

Potencializou-se a necessidade de externalizar a subjetividade iniciada pelos diários tradicionais. O que diferencia, como Silva (2015) aponta, um blog do diário é em relação à forma e a estrutura que esses apresentam, mas a necessidade de expor as memórias e fixar o tempo passado são as mesmas.

Além disso, a fronteira entre autor e leitor é diminuída ao extremo. Antes o autor poderia nem preservar suas escritas para que um dia alguém pudesse descobrir seus diários mesmo que décadas após seu falecimento. Com a era tecnológica, os leitores têm a opção de interagir em cada postagem podendo ou não contribuir com a reescrita do texto o que Silva (2015) interpreta como "fragmentação e modificação de idéias e percursos narrativos".

A memória individual produzida pelos blogs tem intrinsecamente a efemeridade. Eles são usados logo para conversar com os leitores como uma nova modalidade de comunicação. Macedo (2014) comenta que essa comunicação traduz novas formas de identidade que se relaciona ao mundo contemporâneo e conseqüentemente diferenciando-os das gerações mais antigas como relatado por SILVA (2015):

Os jovens possuiriam uma identidade online que se atualiza todo o tempo, conformando parte do ser, da existência e da experiência em um presente, que talvez revele um sintoma de solidão globalizada, ligado a uma fragilidade afetiva que envolve, ao mesmo tempo, o temor à negação diante de tanta exposição. Já os adultos, por sua vez, usam os diários como mais uma estratégia de vinculação com o passado, suas escritas estariam mais próximas de uma "recuperação proustiana do tempo perdido" (SILVA, 2015, p. 16).

Macedo (2014) comenta que os blogs servem também como um meio de ultrapassar a solidão. Estudar blogs e as redes sociais como egodocumentos é estudar o sujeito pós-moderno em sua intimidade real ou idealizada. 
Interessante é análise de Mostacero (2006) faz sobre os textos acadêmicos. Esses são caracterizados pelo seu academicismo, formalismo e objetivismo, além da austeridade e da escrita em terceira pessoa. Contrariando a lógica da falta de emotividade que esses textos teriam devido as suas características, pesquisadores que as utilizam como referências começaram a descobrir subjetividade nos mesmos (MOSTACERO, 2016).

Entre os documentos "familiares" podemos citar o "Livro de Família" que era costume dos nobres judeus produzirem. Segundo Magalhães (2010), o herdeiro da família era o responsável em registrar e preservar os acontecimentos e outros assuntos relativos à sua família. O livro era escrito de forma regular, Iongitudinal, formalmente e que servia para registrar as memórias familiares. Devido ao seu caráter formal, Magalhães (2010) comenta que os historiadores e os tribunais de justiça começaram a utilizá-lo como testemunho.

Os Arquivos Familiares tem algumas particularidades elencadas por Baggerman (2002): são escritos por vários autores no decorrer das épocas, são produzidos mediante uma visão de vida que deve ser repassada para a geração futura e o esquecimento é determinado pelas seleções realizadas por todos que estão na linha de custodiadores desses documentos.

Aníbal (2011) trás um debate sobre os registros de áudios transcritos e fotográficos enquanto egodocumento. Em relação às transcrições, o autor conceitua-os como documentos produzidos pelo sujeito em primeira pessoa de suas memórias e redigidos pelo investigador. Pela presença de dois sujeitos na elaboração desses documentos percebe-se a intencionalidade das mensagens deslocando-se da real personalidade:

O relato escrito pelo investigador é o resultado de uma situação social de algum modo construída, não espontânea: a entrevista/conversa entre entrevistado e entrevistador. A existência de um intermediário altera os termos da situação, pois o investigador não é apenas um tradutor da palavra oral em palavra escrita, a sua simples existência interfere no que é dito. Assim, o que teria sido escrito por aquele sujeito é necessariamente diferente daquilo que ele comunica oralmente ao entrevistador. Entre os dois métodos há diferenças de forma, mas também de conteúdo (ANIBAL, 2011, p. 6).

O pesquisador enquanto intermediário não é um simples transcritor daquilo que foi dito pelo seu depoente, pois ele edita o texto para os seus objetivos. Ao citar Dampièrre (1957) em seu 
argumento Aníbal (2010) comenta que apenas as transcrições fiéis seriam as únicas passíveis de inclusão na classificação como documentos pessoais.

Soma-se a esse ponto de vista o argumento de Conde (1993) citado por Aníbal (2010) a idéia que uma biografia é subjetiva e que o investigador só entra em contato com o ponto de vista de um indivíduo que se encontra dentro de um contexto espacial e temporal. Logo, nas transcrições enquanto biografia, a subjetividade presente é potencializada pelos indivíduos envolvidos em todo o processo e que deve ser considerado por quem estuda esse tipo de fonte.

Os registros fotográficos, por sua vez, constituem traços de personalidade de quem registra e/ou preserva as mesmas. $O$ material utilizado nas fotografias e a técnica do fotógrafo são projetadas no resultado final quanto à qualidade e preferências do profissional. Marcas de personalidade são, portanto, representadas nas imagens quando percebemos o ângulo, objetos, cores, foco e sentido que o fotográfico quis apresentar como Aníbal (2010) relata:

a fotografia permite a criação de representações daquilo que se afigura como mais significativo na vida das pessoas, sendo, por este facto, um importante instrumento de construção identitária considerável valor heurístico para o investigador social (ANíBAL, 2010, p. 8).

As diferentes espécies de egodocumentos proporcionam, como já citado anteriormente, o conhecimento de vários apontamentos sobre a intimidade do titular do acervo. Saber o limite sobre o que e de que forma publicar deve ser uma das preocupações de quem os utiliza como fonte de pesquisa. Dentro da metodologia de trabalho, a ética deve estar presente. Indagações feitas por Magalhães (2010) sobre o ofício do historiador diante desse tipo de fonte completariam o rol de preocupações sobre:

como respeitar a privacidade e a intimidade face e no interior de uma escrita noticiosa, de uma escrita de negócios, de uma escrita de prova; como cruzá-la com outras fontes, uma vez que ela gerou e legitimou a sua própria factologia; como trasladá-la e vertê-la para a narrativa histórica, uma vez que, por exemplo, a sua informalidade, a sobreposição de registros, as eventuais falhas na linguagem, são de si mesmas prova de autenticidade? (MAGALHÃES, 2010. p. 5).

Independentemente de qual espécie de egodocumento a ser utilizada na realização das pesquisas e de qual metodologia 
aplicada para a concretização da mesma, as especificidades apresentadas nesse texto devem ser consideradas para um melhor entendimento do contexto, personagens e fatos neles constantes. É inegável as quantidades de perspectivas de informações que os egodocumentos proporcionam para uma pesquisa, porém é necessário saber dialogar com os vestígios apresentados.

Além da possibilidade de realização de pesquisas com diversos enfoques, o Arquivista, ao deter o conhecimento sobre as características intrínsecas dos egodocumentos, poderá utilizá-las para o tratamento técnico adequado de arranjo e descrição documental. A identificação das motivações ajudará a interpretar o contexto de produção de cada peça documental e assim assimilar a função que se desencadeará na elaboração das séries documentais que comporão o arranjo.

Em sequencia, durante a elaboração do viés de acesso aos usuários, às informações a serem disponibilizadas contarão com maior número de elementos disponíveis aos consulentes do que aquelas mínimas exigidas pelas normas especificas. A apropriação do saber sobre os egodocumentos resultará em acervos melhores organizados e em proliferação de novas pesquisas.

\section{CONSIDERAÇÕES FINAIS}

A historiografia do século XIX e XX impulsionou a utilização dos Arquivos Pessoais enquanto fonte para os diversos tipos de pesquisa devido à valorização desse tipo de acervo. No Brasil, as instituições Arquivísticas começaram a recolher Arquivos Pessoais na década de 1970 iniciando assim o estudo sobre conceitos, tipologias documentais e metodologias de tratamento adequado.

O aumento do número de instituições custodiadoras e de estudos sobre Arquivos Pessoais proporcionou um aprofundamento do tema sob a perspectiva da arquivologia. Porém, a arquivística e seus temas devem buscar novos estágios de aperfeiçoamento e um caminho possível é o diálogo com as outras ciências.

Nesse sentido, esse artigo teve como objetivo contribuir com a arquivística ao apresentar a evolução, conceitos, características e as principais espécies de egodocumentos trabalhados principalmente na historiografia, assim como nas áreas da comunicação e da linguística. A citação do termo "egodocumento" por Camargo e Goulart (2007) impulsionou a pesquisa a um maior conhecimento sobre o tema abordado apenas por elas na área da arquivologia. 
Os fundamentos apresentados sobre egodocumentos nesse artigo deverão ser considerados pelos arquivistas que atuam com esse tipo de documento. É mediante principalmente a identificação e interpretação do contexto social da época em que os documentos foram escritos, as motivações do autor, especificidades da espécie documental utilizada e a forma de transmissão do conteúdo desses que o arquivista desempenhará suas atividades de forma adequada.

O arquivista ao realizar sua pesquisa de contextualização de acervo tendo em vista as características dos egodocumentos apresentados proporcionará mais elementos ao público, seja quantitativamente como qualitativamente, auxiliando substancialmente esses em suas pesquisas. A descrição e a difusão, por exemplo, estarão mais ricas em conteúdo facilitando assim a recuperação informacional. O objetivo da arquivística contemporânea, o acesso à informação, estará não apenas garantida, mas potencializada e qualificada.

O próprio arranjo documental, atividade que deve ser realizada anteriormente a descrição e a difusão, será beneficiado em sua constituição se durante a sua execução for considerado as especificidades dos egodocumentos. A identificação das funções a que respondem um documento devem ser interpretados a luz do contexto temporal e social do mesmo. Dessa maneira, o estabelecimento de séries se aproximará do ideal que responde o acervo em si e facilitará a responder as indagações das diversas pesquisas que poderão surgir.

A variedade de espécie que constituem os egodocumentos é inúmera, desde as clássicas "cartas" passando pelos modernos "blogues" e "redes sociais", pois o que define um egodocumento é a presença de um "eu" estabelecido pelo autor, seja intencionalmente ou não. Alguns documentos que não nasceram para serem egodocumentos, porém contendo elemento do "eu", como por exemplo, os processos judiciais, também poderão ter elementos que os caracterizam como tal como abordado no decorrer do texto.

Ao exporem elementos como a intimidade, sentimentos, personalidade e motivações, além dos apontamentos aqui apresentados, os egodocumentos demonstram também ter uma gama de subsídios que proporcionam um leque de pesquisas acadêmicas (principalmente nas áreas sociais e humanas), além de ajudar no tratamento técnico dos arquivistas para disponibilização dessas fontes, e por esses motivos devem ser continuamente estudados e revisados para a sua devida apropriação. As considerações sobre egodocumentos apresentadas e sobre 0 
benefício que esses darão aos profissionais de Arquivo atingem os objetivos desse artigo.

Recebido em: 20 abr. 2018. Aceito em: 09 set. 2018.

\section{REFERÊNCIAS}

AMELANG, James. Popular autobiography in early modern Europe: many questions, a few answers. Memoria y civilización, v. 5, p. 101-118, 2002.

ANÍBAL, Alexandra. Vidas escritas: para uma tipologia dos documentos pessoais como fontes de uma sociologia à escla individual - o caso dos portefólios reflexivos de aprendizagens. CIES e-Working Papers, n. 117, p. 1-35, 2011. Disponível em: https://repositorio.iscteiul.pt/bitstream/10071/3237/1/WP-CIES117 Anibal.pdf. Acesso em 18 set. 2018.

ARQUIVO NACIONAL. Dicionário de terminologia arquivística. Rio de Janeiro: Arquivo Nacional, 2005. 232 p. Disponível em: $<$ http://www.arquivonacional.gov.br/images/pdf/Dicion Term Arquiv.pdf $>$. Acesso em: 13 set. 2018.

BAGGERMAN, Ariane. The moral of the story: children's reading and the catechism of nature around 1800. In: SMITH, Pamela; SCHMIDT, Benjamin. Making knowledge in early modern Europe. Chicago: University of Chicago Press, 2007. p. 143-160.

BAGGERMAN, Ariane. Travellers time. Nineteenth-century autobiographers and their fight against forgetting In: BARDET, Jean-Pierre; ARNOUL, Élisabeth; RUGGIU, Francois-Joseph. Les écrits du for privé en Europe. Bordeaux: Universitaires de Bordeaux, 2010. p. 65-80.

BAGGERMAN, Arianne. Autobiography and family memory in the nineteenth century. In: DEKKER, Rudolf. Autobiographical writing in its social context since the middle ages. Hilversum: Verloren, 2002. 161-173.

BELLOTTO, Heloísa. Diplomática e tipologia documental em arquivos. Brasília: Briquet de Lemos, 2008. 106 p.

BURKE, Peter. A Escola dos Annales (1929-1989): a Revolução Francesa da historiografia. São Paulo: Editora da UNESP, 1997. 176 p.

CAMARGO, Ana; GOULART, Silvana. Tempo e circunstância: a abordagem contextual dos arquivos pessoais. São Paulo: Instituto Fernando Henrique, 2007. 316 p.

CHARTIER, Roger. A História hoje: dúvidas, desafios, propostas. Estudos históricos. v.7, n. 13, p. 97-113, 1994.

COSTA, C. Amaral, R. Lá Lá Lá Lá Lá Brizola: um nome e uma memória em disputa. Revista Morpheus, v. 9, n. 16, p. 123-142, ago./dez. 2016. 
DEKKER, R. Dutch travel journals from the sixteenth to the early nineteenth centuries. Disponivel em: http://www.egodocument.net/pdf/Dutch Travel Journals.pdf Acesso: em 14 de set. 2018.

DEKKER, R. Egodocuments in the Netherlands from the sixteenth to the nineteenth century. Disponível em: http://www.egodocument.net/pdf/Egodocuments in the Netherlands.pdf Acesso: em 14 de set. 2018.

DEKKER, R. Jacques Presser's heritage: Egodocuments in the study of history. Memoria y civilización, v. 5, p. 13-37, 2002.

DEKKER, R. Watches, Diary Writing and the Search for Self-Knowledge in the Seventeenth Century. In: SMITH, Pamela; SCHMIDT, Benjamin. Making knowledge in early modern Europe. Chicago: University of Chicago Press, 2007. p. 127-142.

FULBROOK, M. RUBLACK, U. In relation: The 'social self' and egodocuments. Germany history, v. 28, n. 3 p. 263-272, Sept. 2010.

GREYERZ, K. Ego-documents: the last-word? Germany history. v. 28, n. 3 p. 273-282, Sept. 2010.

GROF $\beta E$, Sybille. Cartas e correspondência ordinária como egodocumentos na análise linguística. Revista Linguística, v. 11, n. 2, p. 2241, dez. 2015.

LEJEUNE, Philippe. O pacto autobiográfico: de Rosseau a internet. Belo Horizonte: Editora da UFMG, 2008. 460 p.

MACEDO, Ana. Dos diários privados aos blogues: uma expressão temporalmente continuada de intimidade reflexa. In: ARAÚJO, E. Duque, E. FRANCH, M. Tempos sociais e o mundo contemporâneo - as crises, as fases e as rupturas. Braga: Universidade do Minho, 2014.

MAGALHÃES, J. Cadernos de contas de um barbeiro: memórias de monção.

Disponível

em:

http://repositorio.ul.pt/bitstream/10451/5070/1/Pref\%C3\%A1cio\%20a\%20Ern esto\%20Portugu\%C3\%AAs.\%20Cadernos\%20de\%20contas\%20de\%20um \%20barbeiro.pdf Acesso: em 14 de set. 2018.

MOSTACERO, Rudy. Persona y subjetividad em um ego-documento: El caso Roland Barthes. Língua americana. v. x, n. 19, p. 130-142, 2006.

SÁNCHEZ, M. La recuperación de uma memória ausente: Demandas judiciales y relatos de vida em la construcción de la historia de las mujeres. Arenal: revista de historia de mujeres, v. 12, n. 2, p. 211-234, 2005.

SILVA, C. Narrativas digitais sobre os exames de admissão ao ginásio: egodocumentos e cultura escrita na história do tempo presente. Tempo e argumento, v. 7, n. 15, p. 05-41, maio/ago. 2015.

SILVA, W. Saber se inventar: o memorial acadêmico na encruzilhada da 
autobiografia e do egodocumento. Métis, v. 15. n. 30, p. 44-67, jul./dez. 2016.

VÁSSINA, Elena. O último Tolstói como tema da literatura contemporânea: abordagens à analise do gênero documental In: CONGRESSO INTERNACIONAL DA ABRALIC, 12., 2011, Curitiba. Trabalhos... Curitiba: Abralic, 2011. Disponivel em: <http://www.abralic.org.br/eventos/cong2011/AnaisOnline/resumos/TC10461.html >. Acesso em 14 set. 2018. 